\title{
A Study on the Audio-Visual Translation of Noble Love Through the Perspective of Cognitive Psychology of Translation
}

\author{
Peng Yu \\ Correspondence: Peng Yu, School of Foreign Languages, Sichuan University of Science and Engineering, 140\# \\ Longshun Road, Yibin City, Sichuan Province, China.
}

\author{
Received: March 20, 2019 Accepted: April 3, 2019 Online Published: April 3, 2019 \\ doi:10.11114/ijecs.v2i1.4194 URL: https://doi.org/10.11114/ijecs.v2i1.4194
}

\begin{abstract}
Audio-visual translation is a special translation mode with its own peculiarities, which not only has the characteristics of general literary translation, but also is limited by various factors such as film technology and audience acceptance. In the process of audio-visual translation, the translator should take numerous factors into consideration, such as context, audience, and cultural factors etc., which form lots of blockage for subtitle translator. Then, facing plenty of factors, translator should be clear about how to make linguistic choice, and what aspects of subjective factors and cognitive weaknesses he or she need to avoid and overcome. Those issues are what we should make further researches on. In addition, cultural communication capacity is an important symbol of a country's cultural soft power, and it is one of China's current major policies to strengthen the ability of Chinese culture's overseas publicity, which is conducive to re-shaping China's international image and enhancing the international influence of China's culture. Foreigners are especially interested in films and TV programs with Chinese cultural characteristics, and therefore, film and television translation has become a key link of communication between China and the West through film and television culture.

This article is to make a brief evaluation and analysis on the audio-visual translation of Noble Love from the perspective of some relevant theories of cognitive psychology of translation.
\end{abstract}

Keywords: cognitive psychology, noble love, audio-visual translation

\section{Introduction}

Chinese folk stories are rich in content and far-reaching in significance. It is a true portrayal of the daily life, religion and customs of the ordinary people, it is the reflection of the background and social reality of specific time, and it is also an integral part of Chinese culture. Since the founding of new China, the government has paid special attention to the excellent Chinese folk tales in China and has invested considerable energy and material resources in its research, protection, promotion and overseas publicity. Strengthening the external dissemination of films and TV programs with Chinese folk story is conducive to the promotion of China's cultural soft power and the enhancement of China's cultural international influence.

Audio-visual translation is one of the necessary media, and if not handled properly, it is difficult to achieve the effect of communication. This paper, from the perspective of cognitive psychology of translation, makes a brief analysis of some errors in subtitle translation of Noble Love, in the hope of providing some references for subtitle translators.

\section{The Cognitive Psychology of Translation}

Cognitive Psychology of Translation is the discipline which studies systematically the mental activities of translator according to the relevant theory of cognitive psychology and metacognition, which is another major breakthrough in the history of translation theory. Its main research direction lies in the cognition and the behavior mechanism, namely the thought, decision, reasoning, motive and the emotion behind the behavior. As the basic psychological mechanism of human behavior, the core of cognitive psychology is about the acquisition, storage, processing and using. (Wang su, Wang Ansheng, 1992) Translation is not only a linguistic activity, but also a psychological process. Translation studies need to combine translation conversion process with psychological mechanism. The process of language transformation is actually the process of the development of cognition. The relationship between the two should be like this: cognitive psychology, which studies the psychological mechanism of human behavior, is bound to be inseparable from human language and translation is a kind of human activity in language conversion, which involves the translator's psychology. (Liu Shaolong, Zhong Weihe, 2008) 


\section{Noble Love}

The Chinese film Noble Love is about a true folk love story: In the 1950s, Liu Guojiang, a country boy from Chongqing, fell in love with a beautiful widow, Xu Chaoqing, who was 10 years older than him. Being afraid of the negative gossip about their love, they eloped to a remote mountain. To ensure the safety of her getting down the hill, Liu Guojiang spent almost the rest of his life chiseling a mountain road with more than 6000 steps, which is praised as the "stairway of love". However, the audio-visual translation of such a nice movie is to some extent bad.

\section{The Translation of Noble Love from the Perspective of Cognitive Psychology}

\subsection{The Translator's "Weak Consciousness of Language"}

According to cognitive psychology of translation, "language consciousness" refers to the perception of the language and the consciousness of language use. It is mainly reflected in phonetic consciousness, vocabulary consciousness, and language fluency: namely the basic skills (such as vocabulary recognition and decoding, fluency, and the use of vocabulary knowledge) and the linking ability between the readers' existing knowledge and the textual information. (Yan Linhai, 2008)

In the following, the author, based on a paragraph in the film translation of the film "Noble Love", makes a brief comment on the translator's "weak consciousness of language" in the subtitle translation:

\section{你媳妇和你儿子命中相克啊。}

Your wife and son hit with the life.

In this context, when the translator sees the word "Xifu", the translator should, through vocabulary connection, be in accordance with his/her own language consciousness to identify and decode the words in the source language, and then get two ideas in mind: "son's wife" or "daughter in law", and after that selects the most appropriate word according to the context and the linguistic mode of the target language.

However, due to the translator's "weak consciousness of language", when he/she sees the word "Xifu", he/she can only mistakenly, according to the Chinese thinking mode (Chinese "Xifu" is the nickname of the wife) translate the original “你媳妇和你儿子” into “Your wife and son", instead of "Your son and his wife" or other more appropriate translation. Similarly, the translator's later treatment of "命中相克" is also caused by his weak language consciousness.

\subsection{The Translator's "Pre-knowledge Interference"}

To be a translator, he or she should be a reader first and every reader has a certain amount of knowledge stored in his or her head, which is built up through his or her professional history, social experience and work experience etc., namely the pre-existing knowledge. "Pre-knowledge" refers to readers' pre-existing knowledge of the world, which includes readers' pre-existing attitudes, experience and knowledge. Readers' "understanding" of the original text is actually a process of activating and invoking previous knowledge. (Yan Linhai, 2008)

Next, the author, in accordance with a part of context in the film translation of "Noble Love", makes a brief analysis on the translator's "pre-knowledge interference" in the subtitle translation:

\section{人生的姻缘聚合，往往是自己无法预料的。}

The aggregation of life often unpredictable by himself.

According to the cognitive psychology of translation, when a translator reads this paragraph, he/she will firstly activate his/her pre-knowledge of mother tongue for his/her understanding, and then activate his/her pre-knowledge of target language for translating, and finally make appropriate language choices according to the language thinking mode of the target language and the cognitive processing mechanism, which is shown in the figure 1 below:

$$
\text { Reading } \longrightarrow \text { Activating pre-knowledge of mother tongue } \longrightarrow \text { Understanding }
$$

\section{Translating}

However, due to the lack of relevant pre-knowledge, when the translator sees the word "Juhe" in the original text, which means "marriage or divorce", he/she interprets it as aggregation, focus of mathematical or physical reactions and so on, and then activates his/her previous knowledge to translate the source language into "aggregation", resulting 
in improper translation.

\subsection{The Translator's Error of "Lexical Connection Mode"}

In the theories of cognitive psychology of translation, there are many definitions of "psychological lexical database", among which Carroll has given a clear definition: knowledge of words stored in long-term memory, including the meaning, spelling, pronunciation and relevant information (Carroll, 2000). Aitchison, on the other hand, interpreted "mental vocabulary" as words stored in long-term memory, including high and low frequency words (Aitchison, 1994).

Generally speaking, translation is a process of encoding and decoding, and in the process the translator should firstly decode the input-language and obtain its information, and then encode the acquired information into the output-language. The transformation between the two languages inevitably involves the process of withdrawing mental lexicon from one language to another, that is, "mental lexical connection mode". (Yan Linhai, 2008) People build up their own "individual lexical connections" based on their professional history, social experience and work experience, emotions, attitudes, strong memories or life influences etc.

Now, the author intends to make a brief analysis of the translator's "lexical connection mode" error in in the film "Noble Love" :

\section{可谁能想到, ...... \\ But who could think,}

According to the theory of cognitive psychology of translation, when the translator sees the word "想到", he will input it into the brain as the source language, and process the source language through the psychological cognitive mechanism, and then withdraw the corresponding target language in the mental lexicon. When withdrawing the output language of the word "想到", the translator will connect the word in the source language to words in the target language, such as "think, remind, suppose, miss, know...", and finally select a specific target language according to the context.

However, due to the limited knowledge and experience, the translator can only connect the word "想到" in the source language to "think" in the target language. Maybe the translator has too strong lexical connection to the word "think" in the target language, or due to the special "emotional association" of the word "想到" in the source language, the translator, through "emotional connection", finally chose the word "think" in the target language instead of "know" or other more appropriate words.

\subsection{The Translator's "Lack of Artistic Intuition"}

"Intuition" is a special cognitive and psychological ability, which is the perception of things in an instant. Writers and translators often need to rely on this special psychological function, namely artistic intuition, in literary creation or translation. (Yan Linhai, 2008) As far as the cognitive psychology of translation is concerned, the artistic intuition of the translator is reflected in two aspects: in the pre-translation and in the process of aesthetic appreciation of the original text, the translator has a sensitive recognition of a certain word, sentence or artistic image.

\section{打从我懂事的时候起。}

Since I ever remembered

父亲就告诉我,

My father told me

一个人的命运

The fate of a person

是老天安排的。

is the god arranged

你无法改变。

You can not change.

我十六岁那年,

In my six years old,

父亲说为了我的幸福

Father said for my happiness 


\section{把我嫁给家境殿实的沈家。}

Betrothed me to the Shen family.

我原以为这一次坐上花轿

I think this time of sitting the sedan

会是一个女人的最终归宿。

Is ultimate destination of a woman.

可谁能想到

But who could think

人生的姻缘聚合

The aggregation of life

往往是自己无法预料的。

Often unpredictable by himself. This is a monologue at the beginning of the film, which describes the heroine recalling her life experience. With all kinds of emotions, even she herself cannot tell whether god's arrangement for her is good or bad, right or wrong. She was glad and happy that she could get rid of the emotionless marriage to a wealthy "Shen family", and also felt sorry and guilty that she had made her beloved husband work all his life; In addition to its profound literary and artistic characteristics, this monologue also reflects the historical background and social reality of the time.

However, when we read the subtitle translation, those profound literary and artistic characteristics, as well as the historical background and social reality, seem not to be fully reflected:

In this sentence “打从我懂事的时候起, 父亲就告诉我.....”, according to the artistic intuition, the translator should interpret the phrase “懂事起”as"Since the children can understand some reason or the children can understand the old”, instead of "Since I ever remembered", and the reasons are below:

In the first place, this expression, "Since I ever remembered", reflects a slight deficiency of the translator's instinct for the art of translation. For in the translation, "Since I ever remembered, my father told me..." there are grammatical errors, semantic ambiguity, and therefore it does not conform to the western readers' linguistic thinking mode. Secondly, if we back-translate the sentence“Since I ever remembered”, it will be“自从我曾经记得...事情”which means "Since I can remember"; But to western readers it means that there is a time when a child is born and when he or she has memory, usually around the age of three. And this meaning is totally different with the original text "Since the children can understand some reason or the children can understand the old".

The author thinks that this sentence is actually the foreshadowing of the following context: When I was sixteen, my father said he would marry me into a wealthy family for the sake of my happiness. The "Father", in order to make his "daughter" accept "God-arranged fate", instilled in her the secular concept of "marrying rich people" and "arranged marriages" from an early age. Therefore, in translating this part, the translator should not only reflect people's concept of "rich man first" at that time, but also avoid the specific age of the heroine, name the specific time: when does she become "sensible"? With the help of the artistic intuition of translation and the thinking mode of English language, it is more appropriate to translate this paragraph into"When I was a young girl, my father always told me...".

In another sentence,“父亲说为了我的幸福, 把我嫁给家境殷实的沈家”, relying on translator's "artistic intuition", we can understand the significance of the author's highlighting of "the Shen family's very wealth", which reflects the social reality under the background of that time — the upper class and the rich people can manipulate marriages, and the ordinary people hope to change their fate by marrying the rich. Therefore, the attributive modifier in front of "Shen family " cannot be omitted. Unfortunately, the translator of this subtitle has just omitted it and translated it into "Shen family" without any emotional color, which is a little regrettable.

\section{Conclusion}

Totally speaking, audio-visual translation is a special translation mode with its own peculiarities and cultural communication capacity is an important symbol of a country's cultural soft power.

Foreigners are especially interested in films and TV programs with Chinese cultural characteristics, and therefore, film and television translation has become a key link of communication between China and the West through film and television culture. The effort to make evaluation and analysis on the audio-visual translation with Chinese cultural characteristics will definitely pay off for the communication between China and the West through film and television culture. 


\section{Reference}

Aitchison, J. (1994). Words in the Mind: an Introduction to the Mental Lexicon(2nd ed.). Oxford: Blackwell.

Carron, D. W. (2000). Psychology of Language. Bejing: Foreign Language Teaching and Reseach Press.

Liu, S., \& Zhong, W. H. (2008). Psychological Linguistics Study of Interpreting - Construction of "Process" Model of Consecutive Interpreting . Foreign Languages, , 31(4), 86-91.

Wang, S., Wang, A. (1992). Cognitive Psychology [M]. Beijing: Peking University Press.

Yan, L. (2008). Cognitive Psychology of Translation [M]. Beijing: Science Press.

\section{Copyrights}

Copyright for this article is retained by the author(s), with first publication rights granted to the journal.

This is an open-access article distributed under the terms and conditions of the Creative Commons Attribution license (http://creativecommons.org/licenses/by/4.0/). 